\title{
Shortcoming of Measuring Patient Satisfaction's Association With Anemia-Based Cardiovascular Risk in End-Stage Kidney Disease Patients
}

\author{
Hoda Abdolmonem Ahmad ${ }^{\text {a }}$, Dixon Thomas ${ }^{\mathrm{a}, \mathrm{d}}$, Maryam Alrais ${ }^{\mathrm{a}}$, \\ Aaron Burton ${ }^{\mathrm{b}}$, Rajaram Jagdale ${ }^{\mathrm{c}}$
}

\begin{abstract}
Background: Patient-reported humanistic outcomes like patient satisfaction are becoming more important in clinical practice, but their use has limitations. Improvements are needed to better demonstrate how patient satisfaction and clinical outcomes are associated. The objective of the study was to observe the correlation between patient's hemoglobin and patient satisfaction.
\end{abstract}

Methods: A cross-sectional study was conducted at a University Hospital hemodialysis unit among end-stage kidney disease (ESKD) patients on maintenance hemodialysis in February and March, 2021. During this time period patient satisfaction was measured using an instrument from the Choices for Healthy Outcomes in Caring for End-Stage Renal Disease (CHOICE) study. Spearman's correlation coefficient was used to find a correlation between patient satisfaction domains and hemoglobin. $P$ value was set at 0.05 , and SPSS version 26 was used for the analysis.

Results: Out of 41 patients studied, their satisfaction on care by interprofessional staff was $77.3 \%$, information received was $68.8 \%$, and effectiveness of care was $71.3 \%$ for "very good" and "excellent" responses combined. Out of 40 patients, hemoglobin levels were lower in $17(42.5 \%)$ and higher in seven $(17.5 \%)$ patients than the optimal range of $10-12 \mathrm{~g} / \mathrm{dL}$. Spearman's correlation coefficients were not statistically significant for anemia and any patient satisfaction domain $\left(\mathrm{r}_{\mathrm{s}}\right.$ : $0.244,0.101,0.048$, respectively for the three domains). Spearman's correlation coefficients were high or moderate between patient satisfaction domains; interprofessional staff with information $\left(\mathrm{r}_{\mathrm{s}}: 0.745, \mathrm{P}\right.$ value $<0.001)$ and interprofessional staff with the effectiveness of care $\left(\mathrm{r}_{\mathrm{s}}: 0.619, \mathrm{P}\right.$ value $\left.<0.001\right)$. Information domain had a moderate correlation with the effectiveness of care $\left(r_{s}: 0.527, P\right.$ value $\left.<0.001\right)$.

Manuscript submitted November 1, 2021, accepted November 22, 2021

Published online December 8, 2021

${ }^{a}$ College of Pharmacy, Gulf Medical University, Ajman, United Arab Emirates ${ }^{b}$ School of Pharmacy and Physician Assistant Studies, University of Saint Joseph, West Hartford, CT, USA

'Department of Nephrology, Thumbay University Hospital, Ajman, United Arab Emirates

${ }^{\mathrm{d} C}$ Corresponding Author: Dixon Thomas, College of Pharmacy, Gulf Medical University, United Arab Emirates. Email: dixon.thomas@gmail.com

doi: https://doi.org/10.14740/cr1332
Conclusions: No correlation was observed between patient satisfaction with hemoglobin. Although patient satisfaction among hemodialysis patients was mostly "very good" or "excellent", nearly half of the patients were anemic, and some had higher hemoglobin than the target. Since both of these groups have higher cardiovascular risk this provides an opportunity for the development of patient satisfaction tools with greater sensitivity to awareness of patients' cardiovascular risk.

Keywords: Patient satisfaction; Hemoglobin; Cardiovascular risk; Anemia

\section{Introduction}

Most hemodialysis patients have some considerable level of dissatisfaction with their treatment. Survival on maintenance hemodialysis is a challenging and exhausting experience. According to a global survey, patients treated with hemodialysis experience a mortality rate of approximately $15-20 \%$ each year $[1,2]$. On the other hand, many patients who receive three times per week of regular dialysis frequently complain about the influence of the procedure on their everyday life [3]. The everyday life schedule is hampered due to the lack of confidence and discomfort in maintaining a healthy social life. As a result, kidney function failure and its treatment considerably impact the individual's physical, mental, emotional, and social activities. Patient's failure to work in a usual way can have the worst effect on their dissatisfaction in general. These adverse impacts lead to their lack of desire to continue living [4].

Patient satisfaction is an integral part of dialysis care [5]. Patient experience of care is a variable in determining the quality of care [6]. Patients experience of care is influenced by the patients' perceptions of the breadth of interactions with the healthcare system, including care from healthcare team, facilities in general, and health plans. Patients on hemodialysis are relatively less happy with their care due to its complexity. Patients' expectations for accurate information, prognosis, kidney transplantation likelihood, and options when choosing dialysis therapy must be considered [2]. Previous scholarly work has suggested interventions to improve end-stage kidney disease (ESKD) patient's satisfaction. In one study of hemodialysis patients, counseling sessions increased patient satisfaction and 
clinical outcomes [7]. In another article the authors suggested that empowering hemodialysis patients' should be considered in hemodialysis centers to help patients handle health-related difficulties [8]. Patients with ESKD have a variety of comorbidities and must take a variety of drugs. In ESKD patients, improving their humanistic outcomes has become a significant therapy priority [9]. Per the Choices for Healthy Outcomes in Caring for End-Stage Renal Disease (CHOICE) study, peritoneal dialysis patients generally were more satisfied with their overall care and thought their treatment had fewer effects on their lives than hemodialysis patients $[2,10,11]$.

As both patient satisfaction and clinical outcomes are to be improved, their value to be associated is clinically significant [12]. Interdisciplinary collaborations generate health system improvements. These collaborations subsequently improve clinical outcomes, reducing hospital admission and readmission rates, and shorter hospitalization [13].

ESKD causes a considerable financial burden to society [14]. In ESKD receiving hemodialysis, cardiovascular disease is a major cause of death $(42 \%)$ due to secondary complications [15-17]. Despite advances in dialysis technology, cardiovascular mortality of these patients remains high. In addition, several cardiovascular abnormalities occur in the later stages of chronic kidney disease (CKD), such as anemia, left ventricular hypertrophy, myocardial fibrosis, microvascular disease, and arteriosclerosis [18, 19].

Anemia is an independent cardiovascular risk factor in hemodialysis patients [20] resulting from relative erythropoietin deficiency [21]. Low hemoglobin ( $\mathrm{Hb}$ ) levels (less than $10 \mathrm{~g} /$ $\mathrm{dL}$ ) increase the risk of cardiovascular morbidity and mortality [22]. Anemia in CKD often develops early in the disease's progression, often before the requirement for renal replacement treatment. It harms the patient's health and is linked to several comorbidities, including a higher risk of cardiovascular morbidity and mortality [20]. CKD patients understand their anemia and have clear preferences on its management [23]. Recombinant human erythropoietin in ESKD patients on maintenance hemodialysis has improved their anemia [24]. Intricate and detailed information on dialysis choices and prognosis may be critical for improving patient experiences of long-term dialysis care.

The Dialysis Outcomes and Practice Patterns Study (DOPPS) findings highlight the challenges of applying clinical standards in the day-to-day management of individual patients [25]. The findings validated the link between $\mathrm{Hb}$ levels of 11 $\mathrm{g} / \mathrm{dL}$ and prolonged survival in maintenance hemodialysis patients but found no extra survival benefit for those with $\mathrm{Hb}$ levels of $12 \mathrm{~g} / \mathrm{dL}$ [26]. National Kidney Foundation/Kidney Disease Outcomes Quality Initiative (NKF/KDOQI) guidelines recommend target $\mathrm{Hb}$ of 10 to $12 \mathrm{~g} / \mathrm{dL}$ in patients with CKD receiving erythropoietin therapy [27]. A study found a short-term association between $\mathrm{Hb}$ levels and hospitalization rates. The long-term effects of $\mathrm{Hb}$ levels on patient mortality and morbidity require more investigation [28].

It is vital to study patient satisfaction among ESKD patients and its association to anemia-based cardiovascular risk. The primary objective of the study was to observe the correlation between patient's $\mathrm{Hb}$ and patient satisfaction. The secondary objective was to study the correlation between different domains of patient satisfaction instrument.

\section{Materials and Methods}

\section{Procedure and participants}

A cross-sectional study was used to find the association between patient satisfaction with $\mathrm{Hb}$ level. Data were collected in February and March 2021. This is an exploratory study to assess if patient satisfaction domains are associated with one of the cardiovascular risk indicators, $\mathrm{Hb}$. The study site was the Thumbay University Hospital Hemodialysis Unit with 10 beds. Thumbay University Hospital is a private academic hospital in the United Arab Emirates with 350 beds. The patient population contains patients undergoing hemodialysis as part of their ESKD management. It was a population-based study. All hemodialysis patients were included based on inclusion and exclusion criteria.

Inclusion criteria were: patients of 18 to 85 years old, ESKD patients on maintenance hemodialysis, and patients who communicate in English.

Exclusion criteria included: patients on hemodialysis for acute kidney injury, patients have arteriovenous grafts, patients on other forms of hemodialysis like peritoneal hemodialysis, and patients not consenting to take part in the study.

Patient satisfaction was measured by using the CHOICE questionnaire $[2,10]$. It was modified to combine nursing and nephrologist care to interprofessional care. The questionnaire was content validated by two investigators experienced in the field. The investigator filled the questionnaire in discussion with patients undergoing hemodialysis. $\mathrm{Hb}$ levels and patient demographic details were collected from the medical records. The confidentiality of the patients was taken care of. Interactions with patients happened at every dialysis visit with oral consent respecting the comfort and emotion of the patient. This study was approved by the Gulf Medical University Institutional Review Board (IRB); and was conducted in compliance with the ethical standards of the responsible institution on human subjects as well as with the Helsinki Declaration.

\section{Analysis}

Descriptive statistics were used for patient satisfaction (domains, interprofessional staff, information, effectiveness, overall). Spearman's correlation coefficient was used to find the correlation between patient satisfaction domains and $\mathrm{Hb}$. Spearman's rho $\left(\mathrm{r}_{\mathrm{s}}\right)$ value is categorized as following, 0 to 0.3 negligible, 0.3 to 0.5 low, 0.5 to 0.7 moderate, 0.7 to 0.9 high, 0.9 to 1 as very high positive correlation. P value is set at 0.05 , and SPSS version 26 was used for the analysis.

\section{Results}

\section{Participant characteristics}

The patient satisfaction of 41 patients on maintenance hemodialysis was assessed. The study population included 30 
$(73.17 \%)$ males and $11(26.82 \%)$ females, $46.34 \%$ of patients aged between $40-59$, and $41.46 \%$ aged above 60 years old. The majority of patients $(95.1 \%)$ were married. The proportion of employed and unemployed patients was almost the same $(43.90 \%$ and $41.46 \%)$. Two-thirds of patients had diabetic mellitus, and most of them (95.12\%) had hypertension. The majority of the population $(85.36 \%)$ was on charity payment, and only a few of them had health insurance (4.87\%) coverage, and others were on full out-of-pocket payment (9.75\%). Charity covered mostly for the hemodialysis expenses, but medication or laboratory test support was limited. Some patients' diet control was varying, some had mild (34.14\%), and most others had no diet control (41.46\%). Moreover, only $2.43 \%$ had strict diet control. Many patients had high body mass index (BMI) in which fewer than half of them $(44.7 \%)$ were overweight, and $34.2 \%$ were obese; only $21.05 \%$ had normal weight. Approximately two-thirds of the patients $(68.29 \%)$ had three times per week regular dialysis, and $31.70 \%$ of them had two times per week regular dialysis. The participants were from 13 different countries, in which majority of them were from Pakistan, Bangladesh, India, and Egypt.

\section{Patient satisfaction and anemia}

From the available laboratory test data, out of 40 patients, $\mathrm{Hb}$ levels were lower in 17 (42.5\%), and higher in seven (17.5) patients than the range of $10-12 \mathrm{~g} / \mathrm{dL}$ (three among these seven patients were in the border with $12 \mathrm{~g} / \mathrm{dL} \mathrm{Hb}$ ). Nearly half of the patients were anemic at different $\mathrm{Hb}$ levels varying from 6.7 to $9.6 \mathrm{~g} / \mathrm{dL}$. The following laboratory data were available for lesser numbers of patients. Of 31 dialysis patients, twothirds of them had low hematocrit levels, and 16\% had high $\mathrm{Hb}$ levels. More than half of 31 patients had low serum iron levels, and the rest of the patients were in the normal range category. From 16 dialysis patients, almost two-thirds of males and females had a high level of serum ferritin. The rest of the population was in the normal range category. Patient satisfaction on interprofessional care was mainly excellent and very good (Table 1).

The overall patient satisfaction for quality of care the patient has received in the hemodialysis patient center was mostly highly positive. More than half of respondents $(56 \%)$ ranked as excellent care, and $22 \%$ ranked as very good care. However, only a few patients ranked the quality of care as good, fair, and poor.

As shown in the bar chart about the patient recommendation of hemodialysis to a friend or relative who needs hemodialysis, most patients responded as definitely yes and probably yes (Fig. 1).

More than $30 \%$ of patients responded that nothing could be better at all about their hemodialysis care. However, others suggested some things to be improved (Fig. 2).

\section{Correlation}

Table 2 shows the association of $\mathrm{Hb}$ levels with the patient satisfaction domains among the study population. Again, patients' satisfaction domains show association with each other, but none were associated with $\mathrm{Hb}$.

Spearman's correlation coefficient of more than 0.5 is considered to be correlated. Thus, different domains of patient satisfaction are correlated to each other but not with hemoglobin levels.

\section{Discussion}

The hemodialysis patients studied were mostly males and of middle age. Secondary complications apart from kidney disease were very common among these patients, including diabetes and hypertension. The majority of the study population were undergoing three times per week maintenance hemodialysis while others two times per week. Almost all of the patients were expatriates as there were other hemodialysis units by the government in Ajman for the UAE nationals.

Patient satisfaction in all domains interprofessional staff, information, and effectiveness were impressive with room for improvements. Approximately half of the patients were anemic or had higher Hb levels that contribute to their cardiovascular risk. No found correlation existing between patient satisfaction and $\mathrm{Hb}$ shows the potential limitation of this patient satisfaction instrument to be sensitive to detecting individual patient cardiovascular risk.

$\mathrm{Hb}$ levels below $10 \mathrm{~g} / \mathrm{dL}$ often led to left ventricular hypertrophy associated with an increased risk of cardiovascular disease. Left ventricular hypertrophy and left ventricular dilation lead to a higher mortality rate due to cardiovascular disease as a result of kidney disease [22]. The quality of life of patients decreases due to anemia complications [29]. Kidney failure often impacts the patients' physical, mental, emotional, and social activities [30]. Though higher $\mathrm{Hb}$ levels do not ensure the reversal of effects of cardiomyopathy, they still have positive outcomes in terms of decreased rate of left ventricular hypertrophy or dilation [20]. Patients with Hb levels above 11 $\mathrm{g} / \mathrm{L}$ had a longer survival rate [26].

Previous meta-analysis findings revealed an increase in the risk of all-cause mortality in anemic patients with CKD treated with erythropoietin to achieve a higher $\mathrm{Hb}$ target [31]. Such patients are also at a higher risk of arteriovenous access thrombosis and poorly managed hypertension, both of which may contribute to the increased risk of mortality. The analysis illustrates an additional risk of critical adverse events, incorporating death, while $\mathrm{Hb}$ is elevated to $12-16 \mathrm{~g} / \mathrm{dL}$ in such persons. Whereas such a concentration of $\mathrm{Hb}$ is within the standard physiological concentration, any recognized clinical benefits seem to come at the expense of reduced survival in these patients. Therefore, an upper limit for target $\mathrm{Hb}$ level must be measured in future reconsiderations of guideline recommendations [31]. In patients with lower hematocrit levels, the use of erythropoietin results in reduced cardiovascular mortality [32]. Lower hematocrit and a higher need for erythropoietin are predictors of higher mortality rates among the hemodialysis population [33].

To determine whether correction of anemia can improve 
Table 1. Patient Satisfaction on Interprofessional Staff's Care, Information, and Effectiveness

\begin{tabular}{|c|c|c|c|c|c|}
\hline Patient satisfaction domains (items) & $\begin{array}{l}\text { Poor, n } \\
(\%)\end{array}$ & $\begin{array}{l}\text { Fair, } n \\
(\%)\end{array}$ & $\begin{array}{l}\text { Good, } \\
\text { n (\%) }\end{array}$ & $\begin{array}{l}\text { Very good, } \\
\text { n }(\%)\end{array}$ & $\begin{array}{l}\text { Excellent, } \\
\text { n }(\%)\end{array}$ \\
\hline \multicolumn{6}{|l|}{ Interprofessional staff's care } \\
\hline $\begin{array}{l}\text { 1. How well the nephrologist, nurse, pharmacist, } \\
\text { and others you see coordinate with each other }\end{array}$ & $3(7.3)$ & $2(4.9)$ & $5(12.2)$ & $8(19.5)$ & $23(56.1)$ \\
\hline $\begin{array}{l}\text { 2. How much knowledgeable are your nephrologist, nurses, } \\
\text { and pharmacist to explain the disease and medication aspects }\end{array}$ & $2(4.9)$ & $6(14.6)$ & $5(12.2)$ & $9(22)$ & $19(46.3)$ \\
\hline $\begin{array}{l}\text { 4. How sensitive, helpful, and caring your hemodialysis } \\
\text { center nephrologist, nurses, and pharmacist are }\end{array}$ & $1(2.4)$ & $3(7.3)$ & $3(7.3)$ & $11(26.8)$ & $23(56.1)$ \\
\hline $\begin{array}{l}\text { 5. How well your hemodialysis center nephrologist, nurses, and } \\
\text { pharmacist respond when you say you are in pain or uncomfortable }\end{array}$ & $1(2.4)$ & $2(4.9)$ & $1(2.4)$ & $12(29.3)$ & $25(61)$ \\
\hline 6. The number and kind of staff available to help you in an emergency & $2(4.9)$ & $1(2.4)$ & $11(26.8)$ & $9(22)$ & $18(43.9)$ \\
\hline $\begin{array}{l}\text { 8. The amount of information you are being given to help you choose } \\
\text { between different types of dialysis as well as nutrition, and medication }\end{array}$ & $0(0)$ & $6(14.6)$ & $7(17.1)$ & $16(39)$ & $12(29.3)$ \\
\hline $\begin{array}{l}\text { 9. How much information you are given about the amount of fluid to } \\
\text { take in and take off }\end{array}$ & $2(5)$ & $2(5)$ & $5(12.5)$ & $10(25)$ & $21(52.5)$ \\
\hline 10. How involved are in decisions made on your health & $1(2.4)$ & $6(14.6)$ & $7(17.1)$ & $9(22)$ & $18(43.9)$ \\
\hline Overall \% & $2.45 \%$ & $12.2 \%$ & $16.55 \%$ & $28.2 \%$ & $40.6 \%$ \\
\hline \multicolumn{6}{|l|}{ Effectiveness of kidney care } \\
\hline 11. How much fluid is removed during your hemodialysis session & $0(0)$ & $1(2.5)$ & $8(20)$ & $13(32.5)$ & $18(45)$ \\
\hline 12. How well new medical problems are managed when they arise & $0(0)$ & $3(7.3)$ & $7(17.1)$ & $10(24.4)$ & $21(51.2)$ \\
\hline
\end{tabular}

IV: intravenous.

clinical outcomes, large randomized clinical trials (RCTs) using general clinical events and contributing patients with ESKD are required [34]. Based on available RCTs, Hb tar- gets of $12 \mathrm{~g} / \mathrm{dL}$ are related to a lower risk of death in patients with cardiovascular complications and CKD than $\mathrm{Hb}$ targets of $13 \mathrm{~g} / \mathrm{dL}$. Nearly one death was prevented for every 30 pa-

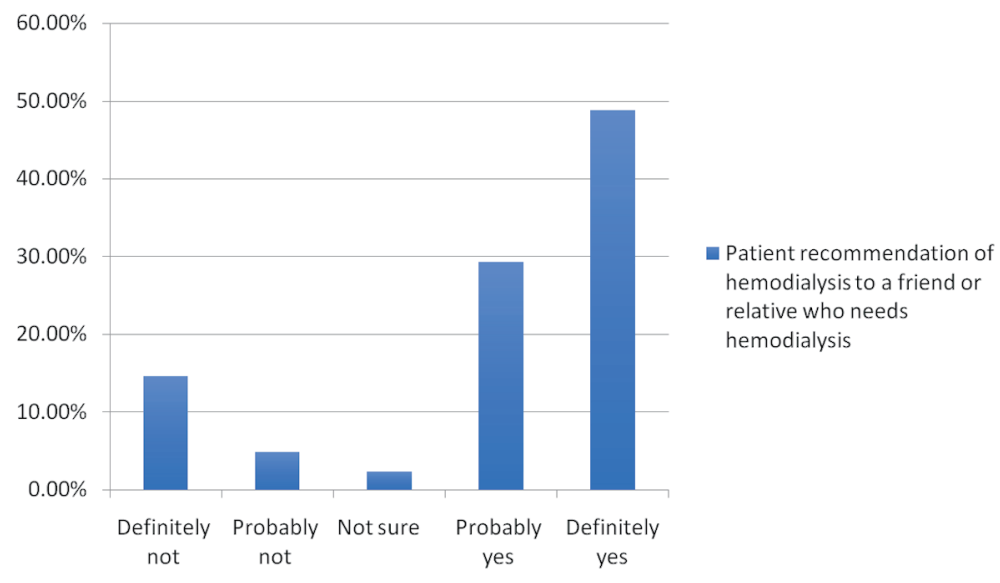

Figure 1. Patient recommendation of hemodialysis to a friend or relative who needs hemodialysis. 


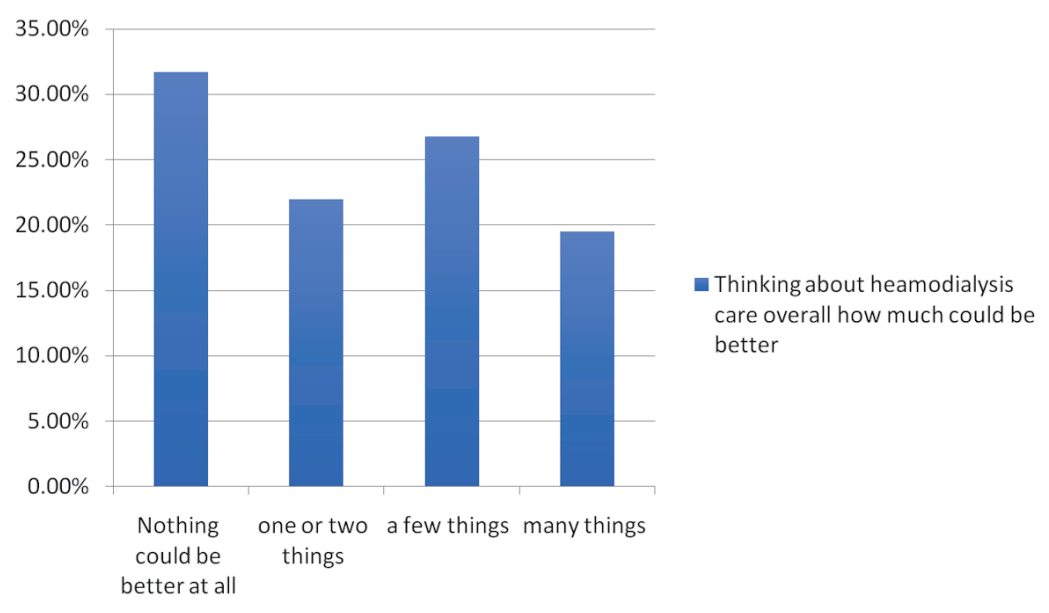

Figure 2. Thinking about hemodialysis care overall, how much could be better.

tients treated to obtain a $\mathrm{Hb}$ target of $12 \mathrm{~g} / \mathrm{dL}$ compared with a $\mathrm{Hb}$ target of $13 \mathrm{~g} / \mathrm{dL}$. These outcomes are relevant mainly to hemodialysis patients with clinical cardiovascular disease. Lower $\mathrm{Hb}$ levels of $9.5 \mathrm{~g} / \mathrm{dL}$ with no erythropoietin treatment are associated with a reduced risk of patients who present with hypertensive episodes. For every seven patients treated to obtain a $\mathrm{Hb}$ level of $10 \mathrm{~g} / \mathrm{dL}$, one patient requires additional antihypertensive medication [35]. The published articles are insufficient to generalize the risks or benefits of a $\mathrm{Hb}$ level greater than $11-12 \mathrm{~g} / \mathrm{dL}$. There is a necessity for well-made RCTs concentrating on mortality as a primary outcome [36].

Correlation between anemia and other clinical or humanistic outcomes was studied in different diseases and was varying [37-41]. Our study found a poor or no correlation between anemia and the treatment effectiveness domain of the CHOICE questionnaire patient satisfaction tool. The CHOICE questionnaire is a broad instrument to measure patient satisfaction, and according to our study might not be sensitive to cardiovascular mortality risks. In the domains of information or effectiveness of care, patient satisfaction needs to be influenced by their cardiovascular mortality risk. If not, a new domain needs to be added and validated to detect prognosis.

Specific patient-reported outcomes instruments need to be developed that are sensitive to the mortality risk of ESKD patients. Though patients are aware of their cardiovascular risk, they may ignore it based on symptomatic relief during the care process. It is necessary to engage patients more in their cardiovascular risk mitigation plans. Patients need to be realistic on their treatment outcome expectation, short- or long-term. Patient satisfaction instrument needs to be sensitive to cardiovascular risk, otherwise the possibilities are vague, patients not being aware of the risk, no realizing seriousness, or ignore their risk intentionally. Disproportional improvement in patient satisfaction without long-term clinical improvement is meaningless.

\section{Limitations}

The patient satisfaction questionnaire was administered while patients were on their regular hemodialysis care. This may be the reason for the higher satisfaction rate. Consistency in survey administration is in fact an advantage. The researcher administered the survey was not involved in those patients' care. The survey was in simple English and any of the study population had difficulty in understanding the questions. Most of the patient population at the hemodialysis unit participated in the study, only 40 - 41 patients. Bigger studies will be more conclusive.

\section{Conclusions}

Patient satisfaction in hemodialysis patients in our study population was rated "very good" or "excellent" in most patients. Also, nearly half of the patients in our study were anemic, and some had higher $\mathrm{Hb}$ than the target; $\mathrm{Hb}$ levels which have higher cardiovascular risk. Patient satisfaction domains were correlated to each other. However, no correlation was observed between any patient satisfaction domains and with $\mathrm{Hb}$ levels. It is recommended to develop patient satisfaction questionnaires that are sensitive to patient awareness of their cardiovascular risks.

Table 2. Correlation of Patient Satisfaction Domains and Hemoglobin

\begin{tabular}{llllll}
\hline \multirow{2}{*}{ I } & Domains & \multicolumn{4}{c}{ Spearman's correlation coefficient $\left(\mathbf{r}_{\mathbf{s}}\right)$} \\
\cline { 3 - 6 } & Interprofessional staff & Information & Effectiveness & Hemoglobin \\
\hline 1 & Interprofessional staff & 1 & $0.745(\mathrm{P}=0.000)$ & $0.619(\mathrm{P}=0.000)$ & 0.244 \\
2 & Information & - & - & $0.527(\mathrm{P}=0.000)$ & 0.101 \\
3 & Effectiveness & - & - & - & 0.048 \\
\hline
\end{tabular}




\section{Acknowledgments}

We thank Professor Jayadevan Sreedharan of Gulf Medical University for statistical support.

\section{Financial Disclosure}

None to declare.

\section{Conflict of Interest}

None to report.

\section{Informed Consent}

Informed consents were obtained from the study participants.

\section{Author Contributions}

HA, DT, MA, and RJ planned the study. HA, MA, and RJ performed data collection. HA, DT, MA, AB, and RJ wrote the article, analyzed the results, reviewed and approved final version of the article.

\section{Data Availability}

The data supporting the findings of this study are available from the corresponding author upon reasonable request.

\section{Abbreviations}

ESKD: end-stage kidney disease; CKD: chronic kidney disease; Hb: hemoglobin; DOPPS: Dialysis Outcomes and Practice Patterns Study; NKF/KDOQI: National Kidney Foundation/Kidney Disease Outcomes Quality Initiative; CHOICE: Choices for Healthy Outcomes in Caring for End-Stage Renal Disease; $r_{\mathrm{s}}$ : Spearman's correlation coefficient

\section{References}

1. Ahmadmehrabi S, Tang WHW. Hemodialysis-induced cardiovascular disease. Semin Dial. 2018;31(3):258-267.

2. Palmer SC, de Berardis G, Craig JC, Tong A, Tonelli M, Pellegrini F, Ruospo M, et al. Patient satisfaction with incentre haemodialysis care: an international survey. BMJ Open. 2014;4(5):e005020.

3. Kshirsagar AV, Tabriz AA, Bang H, Lee SD. Patient satisfaction is associated with dialysis facility quality and star ratings. Am J Med Qual. 2019;34(3):243-250.

4. Dabrowska-Bender M, Dykowska G, Zuk W, Milewska
M, Staniszewska A. The impact on quality of life of dialysis patients with renal insufficiency. Patient Prefer Adherence. 2018;12:577-583.

5. Kirchgessner J, Perera-Chang M, Klinkner G, Soley I, Marcelli D, Arkossy O, Stopper A, et al. Satisfaction with care in peritoneal dialysis patients. Kidney Int. 2006;70(7):1325-1331.

6. Rhee CM, Brunelli SM, Subramanian L, Tentori F. Measuring patient experience in dialysis: a new paradigm of quality assessment. J Nephrol. 2018;31(2):231-240.

7. Moattari M, Ebrahimi M, Sharifi N, Rouzbeh J. The effect of empowerment on the self-efficacy, quality of life and clinical and laboratory indicators of patients treated with hemodialysis: a randomized controlled trial. Health Qual Life Outcomes. 2012;10:115.

8. D'Onofrio G, Simeoni M, Rizza P, Caroleo M, Capria M, Mazzitello G, Sacco T, et al. Quality of life, clinical outcome, personality and coping in chronic hemodialysis patients. Ren Fail. 2017;39(1):45-53.

9. Abraham S, Venu A, Ramachandran A, Chandran PM, Raman S. Assessment of quality of life in patients on hemodialysis and the impact of counseling. Saudi J Kidney Dis Transpl. 2012;23(5):953-957.

10. Rubin HR, Jenckes M, Fink NE, Meyer K, Wu AW, Bass EB, Levin N, et al. Patient's view of dialysis care: development of a taxonomy and rating of importance of different aspects of care. CHOICE study. Choices for Healthy Outcomes in Caring for ESRD. Am J Kidney Dis. 1997;30(6):793-801.

11. Juergensen E, Wuerth D, Finkelstein SH, Juergensen PH, Bekui A, Finkelstein FO. Hemodialysis and peritoneal dialysis: patients' assessment of their satisfaction with therapy and the impact of the therapy on their lives. Clin J Am Soc Nephrol. 2006;1(6):1191-1196.

12. Deshpande PR, Rajan S, Sudeepthi BL, Abdul Nazir CP. Patient-reported outcomes: A new era in clinical research. Perspect Clin Res. 2011;2(4):137-144.

13. Interprofessional Education Collaborative. Core competencies for interprofessional collaborative practice: 2016 update. Washington, DC: Interprofessional Education Collaborative. 2016:1-19. Available at: https://nebula.wsimg.com/2f68a39520b03336b41038c370497473?Acces sKeyId=DC06780E69ED19E2B3A5\&disposition=0\&all oworigin $=1$ (Accessed on October 22, 2020).

14. Himmelfarb J, Vanholder R, Mehrotra R, Tonelli M. The current and future landscape of dialysis. Nat Rev Nephrol. 2020;16(10):573-585.

15. Deligiannis A, D'Alessandro C, Cupisti A. Exercise training in dialysis patients: impact on cardiovascular and skeletal muscle health. Clin Kidney J. 2021;14(Suppl 2):ii25-ii33.

16. Cozzolino M, Mangano M, Stucchi A, Ciceri P, Conte F, Galassi A. Cardiovascular disease in dialysis patients. Nephrol Dial Transplant. 2018;33(suppl_3):iii28-iii34.

17. Drayer RA, Piraino B, Reynolds CF, 3rd, Houck PR, Mazumdar S, Bernardini J, Shear MK, et al. Characteristics of depression in hemodialysis patients: symptoms, quality of life and mortality risk. Gen Hosp Psychiatry. 2006;28(4):306-312. 
18. Chirakarnjanakorn S, Navaneethan SD, Francis GS, Tang WH. Cardiovascular impact in patients undergoing maintenance hemodialysis: Clinical management considerations. Int J Cardiol. 2017;232:12-23.

19. Thomas R, Kanso A, Sedor JR. Chronic kidney disease and its complications. Prim Care. 2008;35(2):329-344, vii.

20. Locatelli F, Del Vecchio L, Pozzoni P. Anemia and cardiovascular risk: the lesson of the CREATE Trial. J Am Soc Nephrol. 2006;17(12 Suppl 3):S262-266.

21. Fishbane S. Anemia and cardiovascular risk in the patient with kidney disease. Heart Fail Clin. 2008;4(4):401-410.

22. Foley RN, Parfrey PS, Morgan J, Barre PE, Campbell P, Cartier P, Coyle D, et al. Effect of hemoglobin levels in hemodialysis patients with asymptomatic cardiomyopathy. Kidney Int. 2000;58(3):1325-1335.

23. Hauber B, Caloyeras J, Posner J, Bromage D, Tzivelekis $\mathrm{S}$, Pollock A. Hemodialysis patients' preferences for the management of anemia. BMC Nephrol. 2017;18(1):1-9.

24. Evans RW, Rader B, Manninen DL. The quality of life of hemodialysis recipients treated with recombinant human erythropoietin. Cooperative Multicenter EPO Clinical Trial Group. JAMA. 1990;263(6):825-830.

25. Locatelli F, Pisoni RL, Akizawa T, Cruz JM, DeOreo PB, Lameire NH, Held PJ. Anemia management for hemodialysis patients: Kidney Disease Outcomes Quality Initiative (K/DOQI) guidelines and Dialysis Outcomes and Practice Patterns Study (DOPPS) findings. Am J Kidney Dis. 2004;44(5 Suppl 2):27-33.

26. Robinson BM, Joffe MM, Berns JS, Pisoni RL, Port FK, Feldman HI. Anemia and mortality in hemodialysis patients: accounting for morbidity and treatment variables updated over time. Kidney Int. 2005;68(5):2323-2330.

27. Besarab A, Bolton WK, Browne JK, Egrie JC, Nissenson AR, Okamoto DM, Schwab SJ, et al. The effects of normal as compared with low hematocrit values in patients with cardiac disease who are receiving hemodialysis and epoetin. N Engl J Med. 1998;339(9):584-590.

28. Chen M, Deng JH, Zhou FD, Wang M, Wang HY. Improving the management of anemia in hemodialysis patients by implementing the continuous quality improvement program. Blood Purif. 2006;24(3):282-286.

29. Silverberg DS, Wexler D, Iaina A, Steinbruch S, Wollman Y, Schwartz D. Anemia, chronic renal disease and congestive heart failure - the cardio renal anemia syndrome: the need for cooperation between cardiologists and nephrologists. Int Urol Nephrol. 2006;38(2):295-310.
30. Hiramatsu T, Okumura S, Asano Y, Mabuchi M, Iguchi D, Furuta S. Quality of life and emotional distress in peritoneal dialysis and hemodialysis patients. Ther Apher Dial. 2020;24(4):366-372.

31. Phrommintikul A, Haas SJ, Elsik M, Krum H. Mortality and target haemoglobin concentrations in anaemic patients with chronic kidney disease treated with erythropoietin: a meta-analysis. Lancet. 2007;369(9559):381388.

32. Brookhart MA, Schneeweiss S, Avorn J, Bradbury BD, Liu J, Winkelmayer WC. Comparative mortality risk of anemia management practices in incident hemodialysis patients. JAMA. 2010;303(9):857-864.

33. Zhang Y, Thamer M, Stefanik K, Kaufman J, Cotter DJ. Epoetin requirements predict mortality in hemodialysis patients. Am J Kidney Dis. 2004;44(5):866-876.

34. Parfrey PS. Target hemoglobin level for EPO therapy in CKD. Am J Kidney Dis. 2006;47(1):171-173.

35. Strippoli GF, Craig JC, Manno C, Schena FP. Hemoglobin targets for the anemia of chronic kidney disease: a meta-analysis of randomized, controlled trials. J Am Soc Nephrol. 2004;15(12):3154-3165.

36. Volkova N, Arab L. Evidence-based systematic literature review of hemoglobin/hematocrit and all-cause mortality in dialysis patients. Am J Kidney Dis. 2006;47(1):24-36.

37. Mancuso A, Migliorino M, De Santis S, Saponiero A, De Marinis F. Correlation between anemia and functional/ cognitive capacity in elderly lung cancer patients treated with chemotherapy. Ann Oncol. 2006;17(1):146-150.

38. Feteh VF, Choukem SP, Kengne AP, Nebongo DN, Ngowe-Ngowe M. Anemia in type 2 diabetic patients and correlation with kidney function in a tertiary care subSaharan African hospital: a cross-sectional study. BMC Nephrol. 2016;17:29.

39. Timiras ML, Brownstein H. Prevalence of anemia and correlation of hemoglobin with age in a geriatric screening clinic population. J Am Geriatr Soc. 1987;35(7):639643.

40. Chaturvedi D, Chaudhuri PK, Priyanka CA. Study of correlation between dietary habits and anemia among adolescent girls in Ranchi and its surrounding area. Int J Contemp Pediatr. 2017;4(4):1165-1168.

41. Datta S, Abraham G, Mathew M, Somasundaram H, Muralidharan TR, Moorthy A, Sathyasekaran, et al. Correlation of anemia, secondary hyperparathyroidism with left ventricular hypertrophy in chronic kidney disease patients. J Assoc Physicians India. 2006;54:699-703. 